\title{
Health technology assessment of magnet therapy for relieving pain
}

\author{
Jalal Arabloo ${ }^{1}$, Pejman Hamouzadeh ${ }^{2}$, Fereshteh Eftekharizadeh ${ }^{3}$, Mohammadreza Mobinizadeh $^{4}$ \\ Alireza Olyaeemanesh ${ }^{4 *}$, Mina Nejati ${ }^{5}$ Shila Doaee $^{5}$
}

Received: 20 Jan 2017

Published: 11 June 2017

\begin{abstract}
Background: Magnet therapy has been used increasingly as a new method to alleviate pain. Magnetic products are marketed with claims of effectiveness for reducing pain of various origins. However, there are inconsistent results from a limited number of randomized controlled trials (RCTs) testing the analgesic efficacy of magnet therapy. This study aimed to evaluate the safety and effectiveness of magnet therapy on reliving various types of pain.

Methods: A systematic search of two main medical databases (Cochrane Library and Ovid Medline) was conducted from 1946 to May 2014. Only English systematic reviews that compared magnet therapy with other conventional treatments in patients with local pain in terms of pain relieving measures were included. The results of the included studies were thematically synthesized.

Results: Eight studies were included. Magnet therapy could be used to alleviate pain of various origins including pain in various organs, arthritis, myofascial muscle pain, lower limb muscle cramps, carpal tunnel syndrome and pelvic pain. Results showed that the effectiveness of magnetic therapy was only approved in muscle pains, but its effectiveness in other indications and its application as a complementary treatment have not been established.

Conclusion: According to the results, it seems that magnet therapy could not be an effective treatment for relieving different types of pain. Our results highlighted the need for further investigations to be done in order to support any recommendations about this technology.
\end{abstract}

Keywords: Magnet therapy, Pain relief, Systematic review

Copyright $\odot$ Iran University of Medical Sciences

Cite this article as: Arabloo J, Hamouzadeh P, Eftekharizadeh F, Mobinizadeh M, Olyaeemanesh A, Nejati M, Doaee Sh. Health technology assessment of magnet therapy for relieving pain. Med J Islam Repub Iran. 2017 (11 June);31:31. https://doi.org/10.18869/mjiri.31.31

\section{Introduction}

Considering the development and changes in the type of disease and emergence of chronic diseases such as arthrodial pains, cancers etc., disease burden and further costs due to using chemical drugs have been considered. This subject not only imposes an enormous cost to the health system, but also the side effects due to the use of drugs have resulted in dissatisfaction of patients and a tendency towards alternative treatments. Currently, the tendency towards alternative treatments in medical science is in-

Corresponding author: Dr Alireza Olyaeemanesh, arolyaee@gmail.com

1. Health Management and Economics Research Center, Iran University of Medical Sciences \& Department of Health Management and Economics, School of Public Health, Tehran University of Medical Sciences, Tehran, Iran.

2. Department of Health Management and Economics, School of Public Health, Tehran University of Medical Sciences, Tehran, Iran.

3. Health Management and Economics Research Centre, School of Health Management and Information Sciences, Iran University of Medical Sciences, Tehran, Iran.

4. National Institute for Health Research, Tehran University of Medical Sciences, Tehran, Iran.

5. Standard and Tariff Office, Ministry of Health and Medical Education, Tehran, Iran creasing. These treatments have been used for a long time, but they are now increasingly used in the West culture. Considering the lower side effects of alternative treatments such as traditional medicine, acupuncture, energy therapy, aromatherapy, chiropractic etc. and because more people want to test such methods hoping to improve their health, more extensive and various brands have entered into the market. One of these alternative treatments that is somewhat known, is magnetic therapy. Despite the fact

$\uparrow$ What is "already known" in this topic:

There are inconsistent results about efficacy of magnet therapy for reducing different types of pain.

$\rightarrow$ What this article adds:

Compared to routine treatments in in relieving different types of pain, our systematic review showed that Magnet therapy is not effective. 
that magnet therapy is attractive for the patients and provides an easy solution for the treatment of pain, and it is relatively safe, durable and noninvasive and easily accessible at the pharmacies and even a few supermarkets, there are no well-known scientific evidences and biological mechanisms to prove its efficacy in relieving pain (1).

Kim (2000) deems magnetic therapy as a normal and noninvasive method, because it uses an external tool such as magnets to treat an area of the body. In the past, the Greece physicians used rings made of iron to treat arthritis. In the $17^{\text {th }}$ century, Germans used magnetic force to treat headache, gout and venereal diseases. Nowadays, the claim of magnetic therapy has advanced from reducing the wounds healing period to the growth of incomplete and dying neonates. The magnets are used to reduce stress and infections, prevent sudden attacks, and improve bones and postsurgical wounds. In general, artificial magnets are divided into two fixed and temporary types, and their energy acts in the magnetic field generated by a series of electrons or the electric current, and its intensity is settable. Most of magnets used for medical and health purposes are of fixed type with a long magnetic impact and varied within 30-5000 gauss. Magnet intensity that is expressed by gauss indicates the number of magnetic lines that are crossed through an area of one square $\mathrm{cm}$. For instance, magnetic virtue of the earth is about 0.5 gauss, whilst the magnetic intensity of magnets used for treatment and pain alleviation was reported to be 300-5000 gauss (2).

These magnets are used in different objects such as special hand and foot wristbands, soft guards, necklace, slipsole, bracelet, back-band and mat, allocating a huge billion dollar industry to itself with the claim of body parts' pain relieving and sedating (3).

These products include magnetic slip soles whose magnets are embedded therein targeting the reflex points for foot resting. Magnetic parts contain neodymium used for increasing the blood circulation, backache and leg pain. Magnetic knee pad is used as a noninvasive pains relief tool, and accelerates blood circulation and sedates the knee pain. Magnetic earrings: Magnetic energy is transferred from the iron existing in the body and provides transfer of oxygen and nutrients for the tissues. This earring acts through pressing points on the ear to control the appetite, relief of headache, neck pain, and jaw problems. Magnetic mats with the power of 3,950 gauss have been called the best therapeutic magnetic tool used to relieve backache, acceleration of blood circulation, treatment of sleeplessness, relief of joints and muscles pain, rheumatoid arthritis and fibromyalgia. Magnetic belt with the power of 1,000 gauss provides the maximum energy of magnetic therapy for the back. Magnetic mask whose gold pieces are embedded therein is operated with the power of 2,500 gauss for facial wrinkles. Magnetic bracelet relieves the carpus, inflammation, stiffness and blood circulation to the ribs outside area and it is claimed that this device can be used to relieve pains in case of arthritis, and the problems of carpal vessel (3). There are many notions in the field of magnets mechanism, some of which believe that magnetic field upon changing the membrane potential reduces the neural depolarization. Some others believe that magnetic field increases the blood flow under the skin and muscular tissues and so reduces the pain (1).

\section{Research Questions}

This assessment article addressed the following question:

What is the safety and effectiveness of magnet therapy for relieving pain?

\section{Study Objectives}

This study aimed to systematically assess the safety and effectiveness of magnet therapy for relieving pain.

\section{Methods}

\section{Literature Search}

This was a systematic review aiming to examine the effectiveness of magnet therapy on reducing pain. In this study, references were searched based on the most important databases including electronic Cochrane Library (Cochrane Reviews (Reviews and Protocols), Technology Assessments and Economic Evaluations) and Ovid Medline from 1946 to May 2014, systematically. According to the manual search via Google browser, three articles were added to the studied articles. At the end of this stage, 20 articles were found. However, after the review, we found that six articles were unrelated, two were found more than once and four were removed due to lack of complete text and abstract. Articles were searched only in English language and after assessing the consistency to the inclusion and exclusion criteria, eight articles were selected for the final stage (Table 1, Figure 1).

\section{Inclusion and Exclusion Criteria}

Study Design

- Systematic reviews were searched originally, as they provided the most reliable forms of evidence.

\section{Intervention}

- Magnet therapy

\section{Population}

- Population of patients with local pains in different organs

\section{Comparators}

- Other conventional healing methods for relieving pain

\section{Outcomes}

Summary of the results were analyzed in six subgroups as follows:

- Pain in various organs

- Arthritis pains

- Myofascial trigger points and myofascial pain syndrome pains

- Lower lime muscle cramps pains

- Carpal tunnel syndrome pains

- Pelvic pains 


\section{Quality Appraisal Method}

Most of the included studies had a desirable quality (using CASP checklist); nonetheless, the quality of the study was not used as a tool to remove the articles.

\section{Synthesizing Method}

Data were extracted from the included studied via a researcher-made data extraction form. Pre-specified outcomes were presented within a descriptive synthesis.

\section{Results}

\section{Literature Search Results}

All the eight articles were systematic review studies (411); of them, one study was conducted in 2014 (5), two studies in $2012(4,7)$, one in 2009 (11), one in 2008 (6), one in 2007 (9) and one in 2006 (10). The summary of the results obtained from the thematic synthesis was analyzed in six subgroups: Pain in various organs, arthritis, myofascial trigger points and myofascial pain syndrome, lower lime muscle cramps, carpal tunnel syndrome and pelvic pain (Table 1, Figure 1).

\section{Summary of Safety and Effectiveness Results}

A. Pain in Various Organs: In the study conducted by Pitler et al. (2007), the results of the analyses revealed no significant difference in pain reduction by magnetic therapy (weighted mean difference [on a $100-\mathrm{mm}$ visual analogue scale] $2.1 \mathrm{~mm}, 95 \%$ confidence interval -1.8 to 5.9 $\mathrm{mm}, \mathrm{p}=0.29$ ). Evidences do not support the use of magnetic therapy for reduction of pain; therefore, magnet therapy may not be recommended as an effective treatment (9).

In the systematic review studies of Colbert el al., 37 studies out of $42(88 \%)$ reported therapeutic profits. The only side effect, exacerbation of hot flushes and skin irritation, was due to adhesives. Most of the studies (34 out of 42 , or $88 \%$ ) reported therapeutic benefits for magnetic therapy (such as pain reduction). Only in one study, the result of magnetic therapy has not been reported positively. In this study, not only patients' pain has not been relieved, but also their skin became red due to the use of magnets. The summary of another study in patients suffering from migraine headache was ineffectual due to the high rate of exclusion from the study (6).

B. Arthritis: In the systematic review of Macfarlane et al., none of the included studies had reported the positive effects of magnetic therapy on pain. However, in some studies of this systematic review, positive effects were observed on the patient's global assessment of pain in specific time points. In one of the included studies in this systematic review, the impact of the device (Magna Bloc), a strong static magnet device having powerful magnetic field, was compared to a similar control device with a weak magnetic power. The patients selected either the strong static magnet device or the weak static magnet device for one week for their knee. Although both groups had reported considerable reduction of pain, no significant

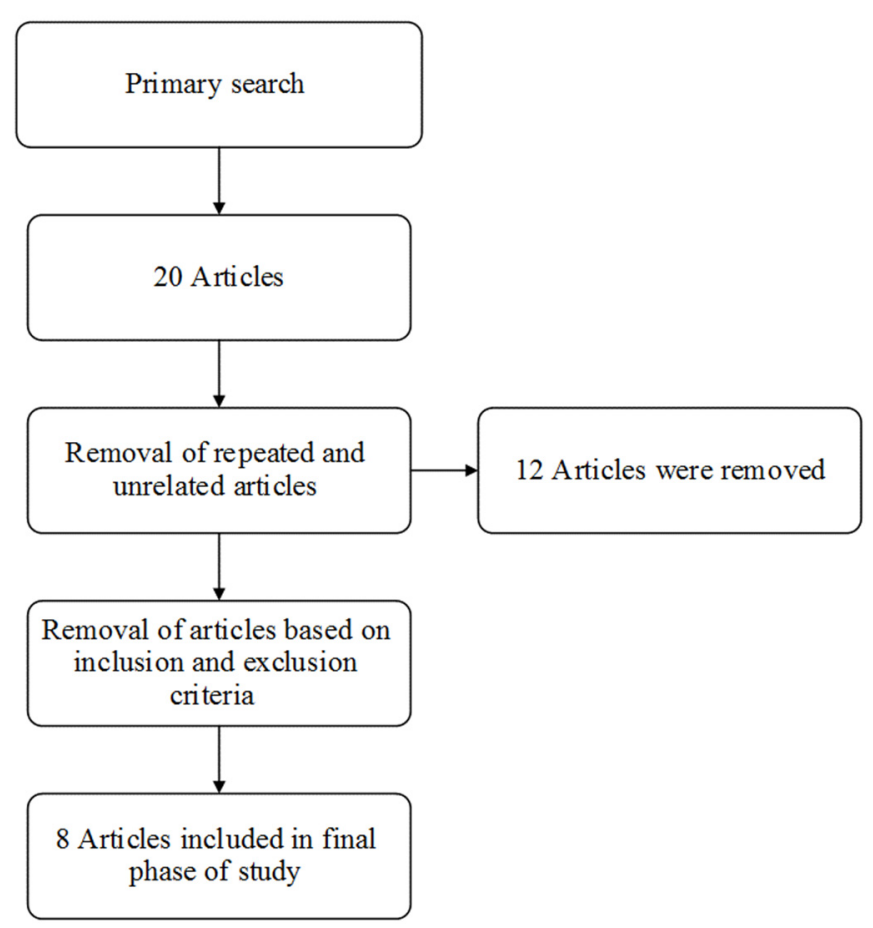

Fig. 1. Flow of the Papers through the Study 


\begin{tabular}{|c|c|c|c|c|}
\hline Author, Year & Setting & Title & Study Design & Inclusion and Exclusion Criteria \\
\hline $\begin{array}{l}\text { Pittler et al., } \\
2007\end{array}$ & UK & $\begin{array}{l}\text { Static magnets for reducing pain: } \\
\text { systematic review } \\
\text { and meta-analysis of randomized } \\
\text { trials (9) }\end{array}$ & $\begin{array}{l}\text { Systematic review } \\
\text { and meta-analysis }\end{array}$ & $\begin{array}{l}\text { Study type: randomized controlled trials. } \\
\text { Intervention: static magnets for treating pain } \\
\text { from any cause } \\
\text { Control: placebo or a weak magnet } \\
\text { Outcome: mean change in pain }\end{array}$ \\
\hline $\begin{array}{l}\text { Macfarlane et } \\
\text { al., } 2012\end{array}$ & UK & $\begin{array}{l}\text { A systematic review of evidence for } \\
\text { the effectiveness of practitioner- } \\
\text { based complementary and alterna- } \\
\text { tive therapies in the management of } \\
\text { rheumatic diseases: osteoarthritis ( } 7 \text { ) }\end{array}$ & Systematic review & $\begin{array}{l}\text { Study type: randomized controlled trials } \\
\text { Intervention: using magnetic therapy, } \\
\text { Control: sham therapy } \\
\text { Outcome: patient's global assessment of pain, } \\
\text { pain reduction }\end{array}$ \\
\hline $\begin{array}{l}\text { Vernon H et al., } \\
2009\end{array}$ & Canada & $\begin{array}{l}\text { Chiropractic management of myo- } \\
\text { fascial trigger points and myofascial } \\
\text { pain syndrome: A systematic review } \\
\text { of the literature (11) }\end{array}$ & Systematic review & $\begin{array}{l}\text { Study type: randomized controlled trials, } \\
\text { Intervention: routine therapeutic methods used } \\
\text { in chiropractic } \\
\text { Outcome: pain relief }\end{array}$ \\
\hline $\begin{array}{l}\text { Blyton et al., } \\
2012\end{array}$ & Australia & $\begin{array}{l}\text { Non-drug therapies for lower limb } \\
\text { muscle cramps (Review) (4) }\end{array}$ & Systematic review & $\begin{array}{l}\text { Study type: randomized controlled trials, } \\
\text { Interventions: all non-pharmacological and non- } \\
\text { invasive interventions used for treatment of } \\
\text { muscle cramps } \\
\text { Outcome: severity and frequency of muscle } \\
\text { cramps, quality of life, participation in daily } \\
\text { activities and Quality of sleep }\end{array}$ \\
\hline $\begin{array}{l}\text { O’Connor et al., } \\
2003\end{array}$ & Australia & $\begin{array}{l}\text { Non-surgical treatment (other than } \\
\text { steroid injection) for } \\
\text { carpal tunnel syndrome (Review) } \\
\text { (8) }\end{array}$ & Systematic review & $\begin{array}{l}\text { Study type: randomized and semi-randomized } \\
\text { controlled trials } \\
\text { Intervention: all non-invasive interventions used } \\
\text { for treatment of carpal tunnel syndrome } \\
\text { Outcome: improvement of clinical symptoms) }\end{array}$ \\
\hline $\begin{array}{l}\text { Rickards et al., } \\
2006\end{array}$ & Australia & $\begin{array}{l}\text { The effectiveness of non-invasive } \\
\text { treatments for active myofascial } \\
\text { trigger point pain: A systematic } \\
\text { review of the literature (10) }\end{array}$ & Systematic review & $\begin{array}{l}\text { Study type: randomized and semi randomized } \\
\text { controlled trials, } \\
\text { Interventions: laser therapy, electrotherapy, } \\
\text { ultrasound, magnetic therapy and occupational } \\
\text { therapy, Outcome: pain severity }\end{array}$ \\
\hline $\begin{array}{l}\text { Colbert et al., } \\
2008\end{array}$ & USA & $\begin{array}{l}\text { Magnets applied to acupuncture } \\
\text { points as therapy - a literature re- } \\
\text { view (6) }\end{array}$ & Systematic review & $\begin{array}{l}\text { Study type: human studies with all study de- } \\
\text { signs and for all clinical indications. } \\
\text { Interventions: acu-magnet therapy } \\
\text { Outcome: therapeutic benefit }\end{array}$ \\
\hline $\begin{array}{l}\text { Cheong et al, } \\
2014\end{array}$ & UK & $\begin{array}{l}\text { Non-surgical interventions for the } \\
\text { management of chronic pelvic pain } \\
\text { (Review) (5) }\end{array}$ & Systematic review & $\begin{array}{l}\text { Study type: randomized controlled trials, } \\
\text { Interventions: nonsurgical methods for treat- } \\
\text { ment of chronic pelvic pain } \\
\text { Outcome: pain reduction }\end{array}$ \\
\hline
\end{tabular}

difference was observed between the two groups in the light of consequences such as pain. The group using highstrength magnet, compared to the low-strength magnet, experienced a significantly greater decrease in their global assessment of disease activity (33\% in comparison to $2 \%$ ). Similarly, the subjective assessment of treatment outcomes in Magna Bloc was significantly better. In addition, the treatment group (68\%) felt better than the control group $(27 \%)$. In this study, no side effects were mentioned. In the two high quality trials, the impact of magnet with high intensity and low intensity was compared. In the first trial, after four hours of therapy, a considerable improvement in pain reduction was observed, using patient's overall assessment, and in magnet with high intensity compared to magnet with low intensity (visual analogue scale: $79 \mathrm{~mm}$ in contrast with $10 \mathrm{~mm}$, pvalue: 0.03 ). Nonetheless, no difference was found for pain reduction in six weeks. A few cases of mild discomfort, confusion, increased pain and stiffness in both groups were reported. In the second trial, more relief was observed in the pain for standard magnet compared to a steel washer group, but not when compared to a weak magnet. In the same systematic review study, in two other trials, the effect of magnet was tested compared to a sham magnet. At first, after a 12 -week therapy period, the pain was significantly reduced. A case of skin irritation was observed as the result of knee packing coverage. In the second trial, the pain reduction after a 2-week treatment period was more in the magnet group than the sham magnet group. In the final trial ( 45 cases), no considerable advantage of magnetic wristband compared to a magnetic or nonmagnetic wristband, was reported in relation to pain reduction (7).

C. Myofascial Trigger Points: Evidences of laser therapy support the electrical stimulation of nerve, acupuncture, and magnetic therapy (on average) for myofascial trigger points syndrome and myofascial pain syndrome; however, the relief and improvement period is different among these methods. Primary evidences indicate that the magnets can be effective in the treatment of these two syndromes (11). In the systematic review study of Richards, it was proved that the use of alternative magnetic stimulation is more effective than placebo in reducing neck muscles pain, and these changes were continued in the three months follow-up. However, this result is under the impact of the heterogeneity of clinical trials included in this study that current evidence did not go beyond the moderate level. Thus, primary evidences suggest that magnetic therapy may be effective for pain reduction; nonetheless, further studies will be required to support 
these findings. Moreover, due to a few side effects of magnetic therapy, it is better to apply a few nonuse cases (10).

D. Lower Limb Muscle Cramps: There are limited evidences for making a decision about the application of nonpharmacological treatment of lower limb muscle cramps. Magnetic therapy is equally effective in treating restless leg syndrome and leg cramps compared to placebo. Further research is required to determine the effectiveness of non-pharmacological treatments for lower limb muscle cramps (primary outcomes included frequency of cramps (cramps time weekly)- secondary outcomes included adverse effects ,cramps severity, cramps period, quality of life related to health, quality of sleep, participation in daily activities) (4).

E. Carpal Tunnel Syndrome: Clinical consequences improvement rate was used to assess the effectiveness of nonsurgical treatments (to steroid injection) on carpal tunnel syndrome compared to placebo or control group. Current evidences indicated significant short-term advantages in the use of edible steroid, splint, ultrasound, yoga, and bone displacement for treating carpal tunnel syndrome. A few evidences suggest that magnetic therapy does not significantly relieve the pain in carpal tunnel syndrome (8).

F. Pelvic Pain: No difference was seen in pain levels at the time of using magnetic therapy compared to a placebo device. No evidences were observed on the advantages in women receiving active magnets who received doubleblind therapy for four weeks compared to those who received placebo magnets with respect to pelvic pain, international clinical severity and pain inability scores of McGill (5).

\section{Discussion}

According to the results, magnetic therapy can be used to reduce pain in various organs, arthritis, myofascial muscle pain, lower limb muscle clamps, carpal tunnel syndrome and pelvic pain. It is concluded that only in myofascial pain syndrome indication, magnetic therapy obtained positive outcomes that two included papers were related to this subject. This results referred to this point that further studies are required to prove the full effectiveness of magnetic therapy $(10,11)$. However, according to the available evidence, magnetic therapy does not seem to have any clinical effectiveness in other indications. Whereas the clinical outcomes of magnetic therapy are currently being studied extensively, we need to increase the clinical trials and perform studies to determine the validity of the results of the present study. It is noteworthy to mention that no evidence was found on the cost of magnet therapy compared to other conventional methods in the included studies. Furthermore, in addition to issues related to safety and effectiveness of magnetic therapy, future studies should be conducted on this type of therapy from economic and cost effectiveness aspects; also, on specifying conditions that magnetic therapy may be a cost-effective treatment strategy. If each one of the magnetic therapy indications be proved, it is necessary to economic studies be applied on its cost-effectiveness in comparison to other therapies, to respond appropriately the urgent need of health policymakers to make decisions related to this technology.

\section{Conclusion}

According to the obtained results, magnetic therapy does not seem to be an alternative for routine treatments in reducing pain and it is only effective in reducing myofascial pain in low evidence level according to the reviewed studies in systematic reviews included in this health technology assessment. According to the summary of the included papers, further studies with more samples seem to be necessary for assessment of efficacy and safety of this technology. Furthermore, the present study may have some limitations, which are as follows: In the present study, only English articles were included, whilst the application of magnetic therapy is prevalent in China and Japan and many articles have been published on this subject in these two countries.

\section{Acknowledgements}

This study was conducted with the financial support of IR Iran's National Institute of Health Research, Tehran University of Medical Sciences; Contract No. 241/M/91278.

\section{Conflict of Interests}

The authors declare that they have no competing interests.

\section{References}

1. Cepeda MS, Carr DB, Sarquis T, Miranda N, Garcia RJ, Zarate C. Static magnetic therapy does not decrease pain or opioid requirements: a randomized double-blind trial. Anesth Analg. 2007;104(2):290-4

2. Ratterman R, Secrest J, Norwood B, Ch'ien AP. Magnet therapy: what's the attraction? J Am Acad Nurs Pract. 2002;14(8):347-53.

3. Anonymous. How Magnetic Therapy Works? [cited May 2014]. Available from: URL:http://www.magnetictherapysales.com.

4. Blyton F, Chuter V, Walter KE, Burns J. Non-drug therapies for lower limb muscle cramps. The Cochrane Library. 2012.

5. Cheong YC, Smotra G, Williams ACdC. Non-surgical interventions for the management of chronic pelvic pain. The Cochrane Library. 2014.

6. Colbert AP, Cleaver J, Brown KA, Harling N, Hwang Y, Schiffke HC, et al. Magnets applied to acupuncture points as therapy-a literature review. Acupunct Med. 2008;26(3):160-70.

7. Macfarlane GJ, Paudyal P, Doherty M, Ernst E, Lewith G, MacPherson $\mathrm{H}$, et al. A systematic review of evidence for the effectiveness of practitioner-based complementary and alternative therapies in the management of rheumatic diseases: osteoarthritis. Rheumatology. 2012;51(12):2224-33.

8. O'Connor D, Marshall SC, Massy-Westropp N, Pitt V. Non-surgical treatment (other than steroid injection) for carpal tunnel syndrome. The Cochrane Library. 2003.

9. Pittler MH, Brown EM, Ernst E. Static magnets for reducing pain: systematic review and meta-analysis of randomized trials. CMAJ. 2007;177(7):736-42.

10. Rickards LD. The effectiveness of non-invasive treatments for active myofascial trigger point pain: a systematic review of the literature. Int J Osteopath Med. 2006;9(4):120-36.

11. Vernon H, Schneider M. Chiropractic management of myofascial trigger points and myofascial pain syndrome: a systematic review of the literature. J Manipulative Physiol Ther. 2009;32(1):14-24. 